\title{
FEATURES OF INTRODUCING BLOCKCHAIN TECHNOLOGY IN DIGITAL ECONOMY DEVELOPING CONDITIONS IN UZBEKISTAN
}

\author{
Elnorakhon Muminova ${ }^{1}$, Guzal Honkeldiyeva ${ }^{1}$, Konstantin Kurpayanidi ${ }^{1{ }^{1,},}$, Shokhistakhon \\ Akhunova $^{1}$, Sevarakhon Hamdamova ${ }^{1}$
}

${ }^{1}$ Ferghana Polytechnic Institute, 150107, Fergana, Uzbekistan

\begin{abstract}
Annotation: The article presents blockchain technology for developing national digital economy, efficiency of digitalization and basic principles of digitalization, and a set of blocks requiring material resources. The purpose of the article is to study features of digital economy development and propose application of blockchain technology in national economy sphere. Research methods: The instrumental and methodical apparatus of research based on application, in framework of a systematic approach, general scientific research methods. Implementing blockchain technology in financial system at micro-macro degrees, insurance system, system of government, electron trade system, industrial system, intellectual property account system, education system, health care system was analyzed in this article. Organizing in perfect way the operations to implement the digital economy in Uzbekistan, and develop and establish large financial projects at the state level, moreover, illustrated in details importance of using blockchain technology in national economy industries while developing and establishing large financial projects at the state level.
\end{abstract}

\section{Introduction}

\begin{abstract}
A number of measures are taken to develop national economy, strengthen macroeconomic stability, attract foreign investments, industrial modernization and creation of modern hightech industries. The analysis carried out today requires the efficient implementation of tasks on complex socio-economic development, the need to timely identify and address the problems that hinder the ongoing reforms in the country. In particular, there is a unified project management system that ensures high-quality organization, coordination, monitoring and control over the process of developing and implementing large-scale public finance
\end{abstract}

\footnotetext{
* Corresponding author:w7777@ mail.ru
} 
projects; insufficient implementation and transparency in the development and implementation of state and regional programs, investment projects We see that the low level of financial resources in this regard leads to misuse and mismanagement and misuse. Also, the lack of a single information platform integrated with databases of government agencies, business entities, state enterprises and organizations to ensure transparency in the process of public procurement is at the heart of today's introduction of blockchain technologies in the economy. The introduction of blockchain technology in all sectors of the national economy would enhance the effectiveness of the analysis and evaluation of the feasibility, justification and profitability of all financial investment projects, their value and other signs of abuse.

\section{Literature review}

The development of the digital economy is closely linked to the issues of further structural transformation of the economy, public administration, as well as the creation of new models of interaction between the state, business and population based on digital technologies.

Eric Brynjolfsson and Brian Kahin first discussed the issues of digitization of the economy in the mid-1990s, with the first definitions being made as a means of bringing together businesses and consumers in the virtual world.

By the end of the 1990s, the analysis mainly focused on ways to increase economic efficiency in enterprises through the use of the Internet in the economy. The impact of the Internet resource on the digitization of the economy has been widely evaluated and discussions on its hidden capabilities have begun. There has been some data on the issues that are the basis of the digital economy, the mechanism of transition to the digital economy, and the hashing functions that are an important element of cryptography [5,6]. Subsequently, the logic of the transition from cryptography to digital currencies, the main types of cryptocurrencies and their properties are reflected in the works of Michael Crosby [7].

The topic explored the possibilities of blockchain technology and the research of scholars who are currently pursuing high-growth economies using this technology. Specifically, Singh, S, Singh. - Blockchain: The Future of Financial and Cyber Security [8], Fu, D., Fang, L: Blockchain Accounting for Social Networking [9], Hu, X., Weber, I., Staples, M.: Architecture taxonomy of blockchain-based systems for design [10], Wan, Z., Lo, D., Xia, X $\therefore$ Characteristics of blockchain systems error: empirical studies at the state level [11], Porru, S., Pinna, A., Marchesi, M: Blockchain Software: Challenges and New Directions [12], Halpin, H., Piekarska, M.: Blockchain Security and Privacy [13], Ahram, T., Sargolzaei, A.: Blockchain Technology News [14], Bdiwi. , R., de Runz, C.: blockch New popular teaching methods based on yn technology [15], Nakasumi, M.: Blockchain technology based supply chain [16], Chen, Z., Zhu, Y.: Blockchain technology: case studies, prospective plans and challenges [17], scientific researches

\section{Methodology}


As a result of rational economic reforms to develop, update and modernize our economy, today the innovative economy is being developed. In particular, the issues of effective corporate financial management in the activity of business entities, the use of blockchain technologies in their financial planning. The following methods were used to study the role and importance of blockchain technologies in the digitization of the national economy.

1. The role of e-commerce in e-commerce has been explored in the digitalization of corporate financial management.

2. The directions of efficiency achieved by digitization of the national economy are described.

3. Analysis of the use of Blockchain technologies at the national level.

\section{Discussion and results}

It should be noted that a number of measures have been developed to date. In particular, on December 17, 2019 in Sedjong, Republic of Korea, the Agreement was signed between the National Project Management Agency under the President of the Republic of Uzbekistan and the Ministry of Public Administration and Security of the Republic of Korea. Under this agreement, Korea will provide $\$ 2$ million in grant assistance to the development of egovernment of the Republic of Uzbekistan. In addition, a delegation from the National Agency participated in the International Forum on Digital Economics and Blockchain Technology held in Heikou, China, December 5-6, 2019. Development and implementation of innovative technologies in China (Artificial Intelligence, Big Data, Internet of Things, Blockchain) and the Hainan Free Economic Zone, the first specialized pilot zone for the implementation of promising projects, mainly in the real sector (industry, agriculture, medicine). The Delegation of the Agency held working meetings with the Directorates of the Hainan Resort Software Community Group, the Hainan Free Trade Zone Blockchain Pilot Zone, and the representatives of Innovation Intelligence Union Group Company, Huobi Group and WeiZhongJie. Hainan visited the Blockchain Research Institute and iSchool, an innovative high school.

In accordance with the Decree of the President of the Republic of Uzbekistan No. PD-3832 dated July 3, 2019 "On Measures for the Development of Digital Economy in the Republic of Uzbekistan" the Ministry of Water Resources of the Republic of Uzbekistan signed an agreement on creation of conditions for the introduction and development of digital economy. implement the measure. The personalized intelligent system implements LPWan and Internet of Things technology and organizes a dispatching system using any device (tablet, smartphone, laptop), stationary computers through the WI-FI, GSM communication channels. The modules and sensors included in the system have autonomous power supply and built-in software and are controlled by a central unit through a radius of up to $3 \mathrm{~km}$.

The Center for E-Government and Digital Economy Projects Management under the National Project Management Agency, UZINFOCOM, and the Extra-Budgetary Pension Fund under the Ministry of Finance of the Republic of Uzbekistan launched a new interactive state service on pension / pension information. You can find the following information: amount of pensions, date of appointment, pay period, length of service, type of pension ngan 
term of service, as well as the amount of the payment and reporting information. All the necessary information can be obtained in real time without any additional documents. This service is provided in the section "Social security" of the Single interactive state services portal, which is provided free of charge to individuals (pensioners / beneficiaries). Updated version of the Single interactive state services portal. In the novelty of the Portal, users will be able to get acquainted with all government services without the mandatory authorization of a single identification system. The portal provides its users with a great opportunity to access 166 types of public services, search for relevant information, address entrepreneurship issues and many more. As noted above, the portal's changes include the introduction of new technologies in the socio-economic sectors of the country, public services and business development. and the creation of additional favorable conditions.

The Agency is introducing an automated information system "Monitoring and monitoring of investment projects implementation". As a result of this system, it will be possible to monitor timely and qualitative implementation of the Investment and local programs on implementation of investment and infrastructure projects throughout the country. In addition, the system has the following capabilities: automation of project accounting, control and monitoring of project implementation, control over timelines, budget, goals and indicators of projects, reliable investment in attracted and utilized volumes of foreign direct investments data generation; risk of timely commissioning of projects Monitoring of achievement of target indicators provided by the project documents during the post-investment period.

The development of the digital economy is closely linked to the issues of further structural transformation of the economy, public administration, as well as the creation of new models of interaction between the state, business and population based on digital technologies. The head of state noted that digitization of the economy would allow not only growth of GDP by at least $30 \%$, but also a significant reduction in corruption in the society.

Also, according to the Decree of the President of the Republic of Uzbekistan № PD-5624 dated January 10, 2019, the Center for E-Government and Digital Economy Projects Management was established at the National Project Management Agency under the President of the Republic of Uzbekistan. Activity of the Center:

Development of future strategic directions, common approaches, mechanisms and stages of implementation of projects in the field of information and communication technologies within the framework of development of "Electronic Government" system and implementation of "Digital Uzbekistan-2030" program;

systematic monitoring of the development and implementation of projects and the formation of rating assessments of the effectiveness of information and communication technologies in the activities of government agencies and organizations within the framework of programs;

formation of conceptual and methodological basis for the introduction of "smart" and other promising technologies in various sectors of the economy, as well as large-scale data processing technologies;

Conducting the system of collection, processing and accounting of statistical data that characterizes the level of development of the "electronic government" system in accordance with international standards; 
Further development of the infrastructure of the "electronic government", the Single interactive state services portal of the Republic of Uzbekistan and the Unified billing system, which calculates the amount of state duties and fees paid for public services, including on the basis of public-private partnership.

Digital Trust Fund for the Development of Digital Economy According to the Decree of the President of the Republic of Uzbekistan Shavkat Mirziyoev № PD-3927 of September 2, 2018, the Digital Trust Fund was established. supports educational activities in the field of blockchain training and startups, and with foreign and international organizations in the field of cryptocurrency and blockchain. assist in the organization of cooperation.

\section{Description of efficiency of digitization of economy}

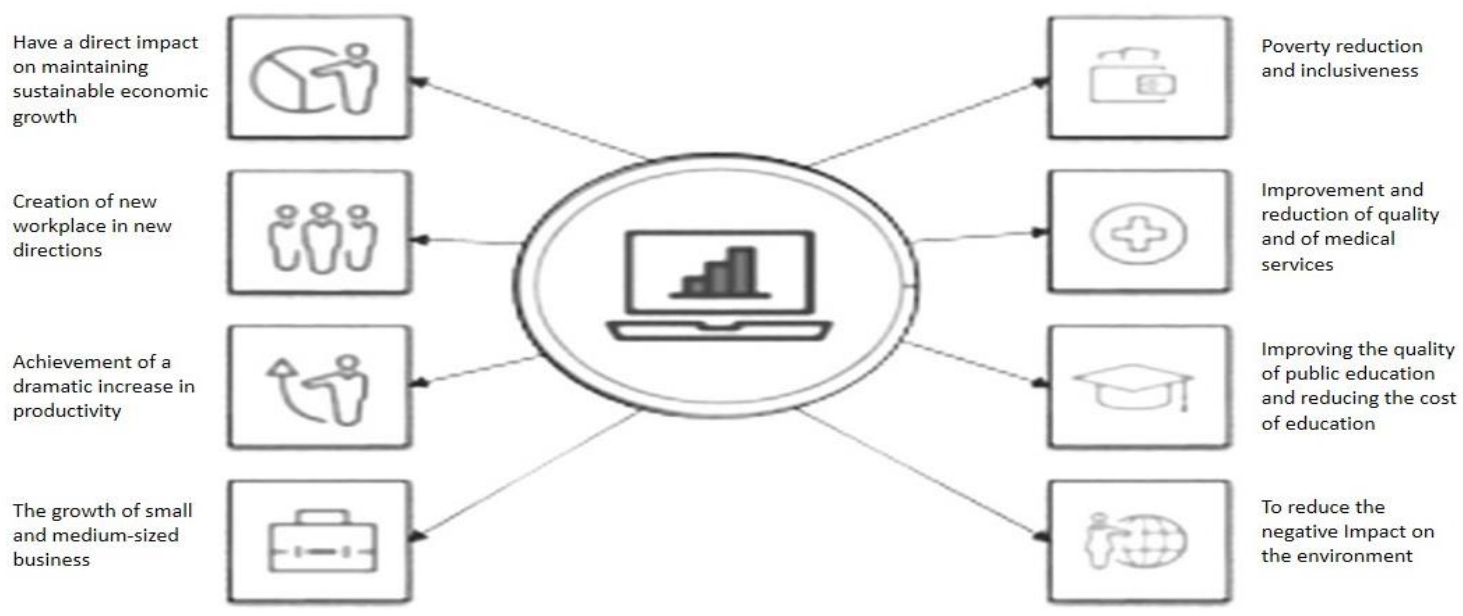

Fig. 1. Characteristics of efficiency trends achieved by digitization of the national economy

It is planned that the Fund will implement blockchain, crypto-assets, purchase of shares and shares in the authorized capital of companies in the digital economy, allocation of grants and loans to support startups, and development of the digital economy. Figure 1 shows the efficiency gains achieved by digitization of the national economy and covers almost all.

Figure 2 summarizes the key principles of digitalization of the economy and the resources available, including the importance of resources such as human capital, the creation of new business models, and technological capabilities at various levels. The use of blockchain technology is an important step in the digitization of the economy. Blockchain technology is a bubble transaction and can be recognized as a special accounting ledger consisting of blocks and page sequences. In this special notebook the number and signature of each block are displayed. One of the achievements of Blockchain technology is that the data entered into the database can be modified only with the consent of $100 \%$ of all users who have signed in. And the lack of trust in the infrastructure provider completely ensures the independence of this technology. It is also possible that any participant involved in Blockchain technology can 
independently conduct an independent audit in the areas of interest. As a result of this technology, it is possible to quickly and inexpensively make any transaction and optimize transaction costs.

\section{The basic principles of the digital economy}

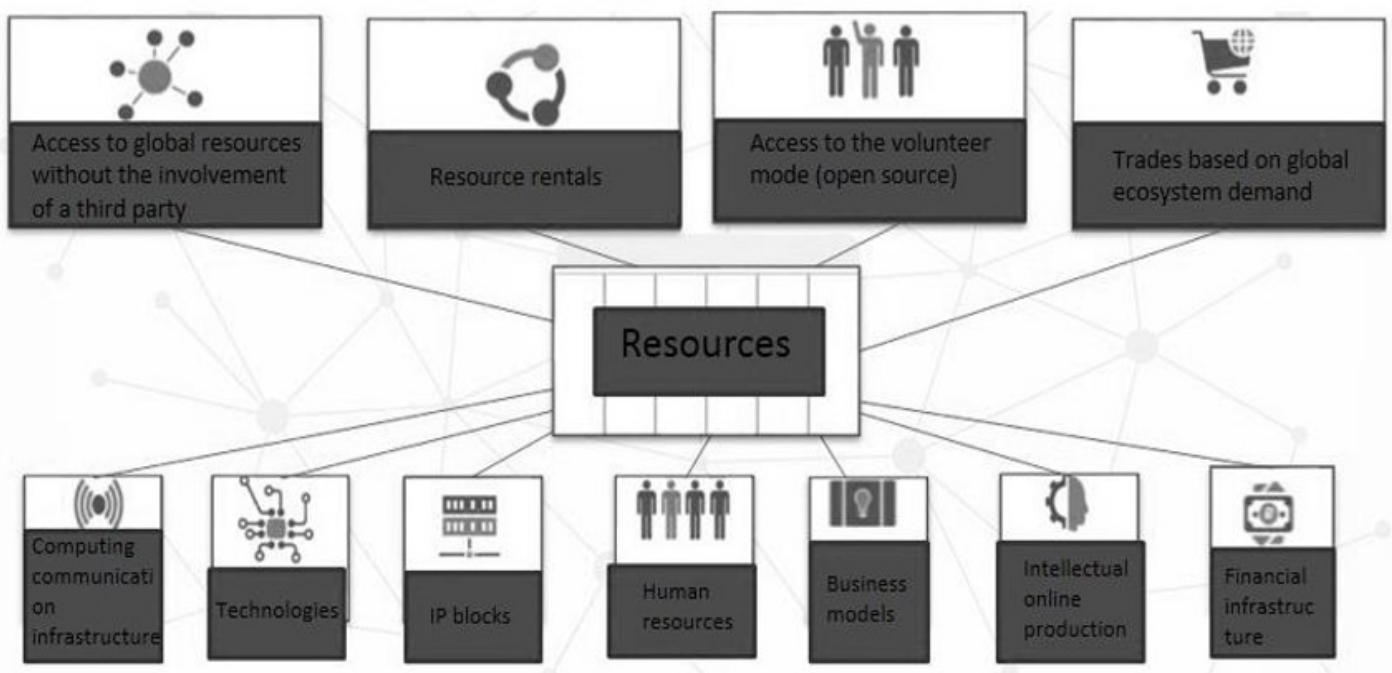

Fig. 2. The basic principles of the digital economy areas.

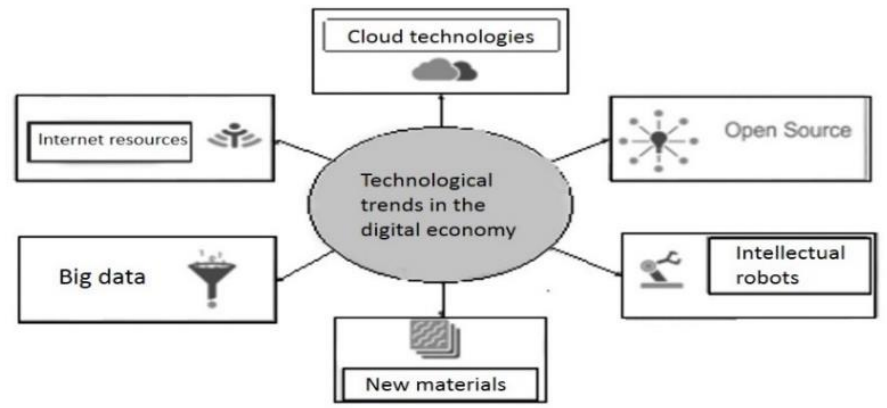

Fig. 3. A set of technologically demanding blocks in the digitization of the economy 
Figure 4 illustrates the geolocation of blockchain technology across the state, with cryptocurrency payments, property registration, voting technology, identity identification, delivery chain management, health care, power of attorney, state registration of legal entities. These are introduced into the taxation system and the state pension system. Of course, in the process of digitization, the implementation of blockchain technology can also cause some problems. In particular, the financial and economic processes require full coverage, lack of human resources and the need for continuous increase, the need for uninterrupted power supply, and high availability of internet resources. However, the introduction of this technology can significantly reduce the cost of public services, including education, health

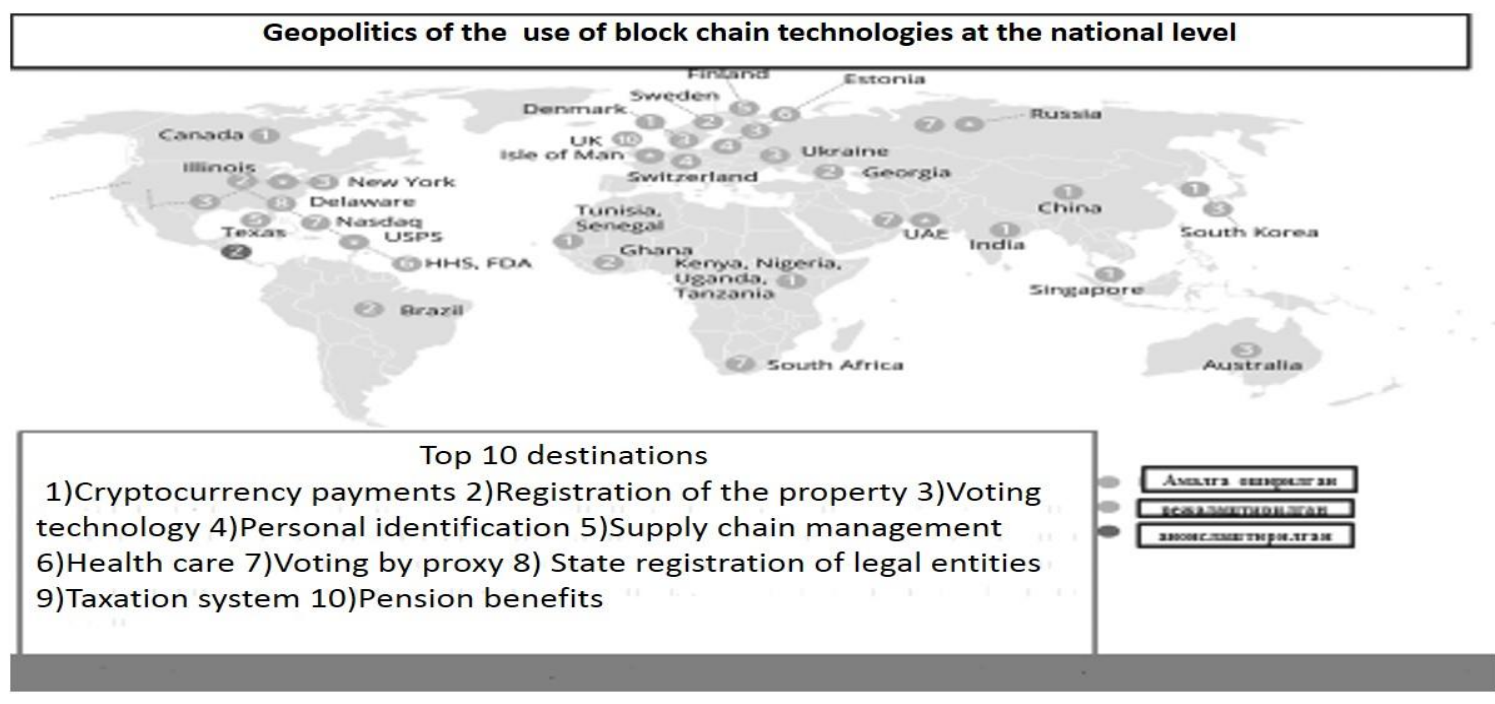

Fig. 4. Geolocation of Blockchain Technology Used at Country Level

care and financial services, to improve their quality and dramatically increase overall coverage. According to world practice, the introduction of these technologies in the economy will not only accelerate the digitization process, but will also have a significant impact on the creation of new business models, accelerating technological and revolutionary processes, accelerating the transformation of various industries and sectors, improving production efficiency and optimizing value creation.

\section{Conclusion}

In conclusion, it should be noted that Uzbekistan should switch to the practice of using blockchain technologies to accelerate the digitization process of the national economy. Also:

Achievement of short-term increase of local staff capacity by attracting foreign experts to increase the speed of use of new information technologies in the digitalization process;

Achieving the frequency of special trainings for IT specialists and accelerating the process of adapting software products to specific areas of the national economy; 
to open an IT academy that can provide training, retraining and continuing professional development services for content-based vendor and accessory software products, stock-halls, professionals working in coworking centers, who can control data center operations;

Provision of special benefits package for IT business development;

Development of preferential crediting mechanism for IT projects, including the introduction of minimum lending limits based on European experience;

intellectual product or royalty improving the licensing legislation of the country.

\section{References:}

1. K. Kurpayanidi, "Management of innovative activity on industrial corporations/Lap Lambert Academic Publishing." (2016).

2. E. A. Muminov, "Modern approaches to defining the nature and function of national innovation system of the Uzbek economy." , 1 (75-85) (Theoretical \& Applied Science 2016) 3. Ahram, Tareq, Technology \& Engineering Management Conference (TEMSCON). (IEEE 2017)

4. Brynjolfsson, Erik, and Brian Kahin, eds. Understanding the digital economy: data, tools, and research, (MIT press, 2002)

5. Nofer, Michael, Business \& Information Systems Engineering, 59.3, 183-187. (2017):

6. Zhang, Yu, and Jiangtao Wen. Peer-to-Peer Networking and Applications 10.4 , 983-994. (2017)

7. Crosby, Michael, Applied Innovation, 2.6-10, 71 (2016)

8. S. Singh, N. Singh, Blockchain: future of financial and cyber security, In: 978-15090-5256-1/16/PP463-467 ( IEEE 2016)

9. D. Fu, L. Fang, Blockchain-based trusted computing in social network. In: 2nd International Conference on Computer and Communications, 978-1-4673-9026-2/16/IEEE (2016)

10. X. Xu, I. Weber, M. Staples, L.Zhu, J. Bosch, L. Bass, C. Pautasso, P. A. Rimba, taxonomy of Blockchain-based systems for architecture design. In: International Conference on Software Architecture 978-1-5090-5729-0/17 (IEEE 2017)

11. Z. Wan, D.Lo, X. Xia, L.Cai, Bug characteristics in Blockchain systems: alargescale empirical study. In: 14th International Conference on Mining Software Repositories 423-424 (IEEE/ACM 2017)

12. S. Porru, A. Pinna, M. Marchesi, R. Tonelli, Blockchain-oriented software engineering: challenges and new directions. International Conference on Software Engineering Companion, 39 (169-179) (IEEE/ACM 2017)

13. H. Halpin, M. Piekarska, Introduction to security and privacy on the Blockchain. In: European Symposium on Security and Privacy Workshops, 1-3 (IEEE 2017)

14. T. Ahram, A. Sargolzaei, S. Sargolzaei, J. Daniels, B. Amaba, Blockchain 978-15090-1114-8/17/ Technology \& Engineering Management Conference (TEMSCON) (IEEE 2017)

15. R. Bdiwi, C., de Runz, S. Faiz, A.A.Cherif, International Conference on Advanced Learning Technologies 17 (101-102) (IEEE 2017)

16. M . Nakasumi, Information sharing for supply chain management based on block chain technology. 140-149 (IEEE 2017) 
17. Z. Chen, Y. Zhu, personal archive service system using Blockchain technology: case study, promising and challenging. In: International Conference on AI \& Mobile Services (AIMS) 978-1-5386-1999-5/17, 93-99 (IEEE 2017) 